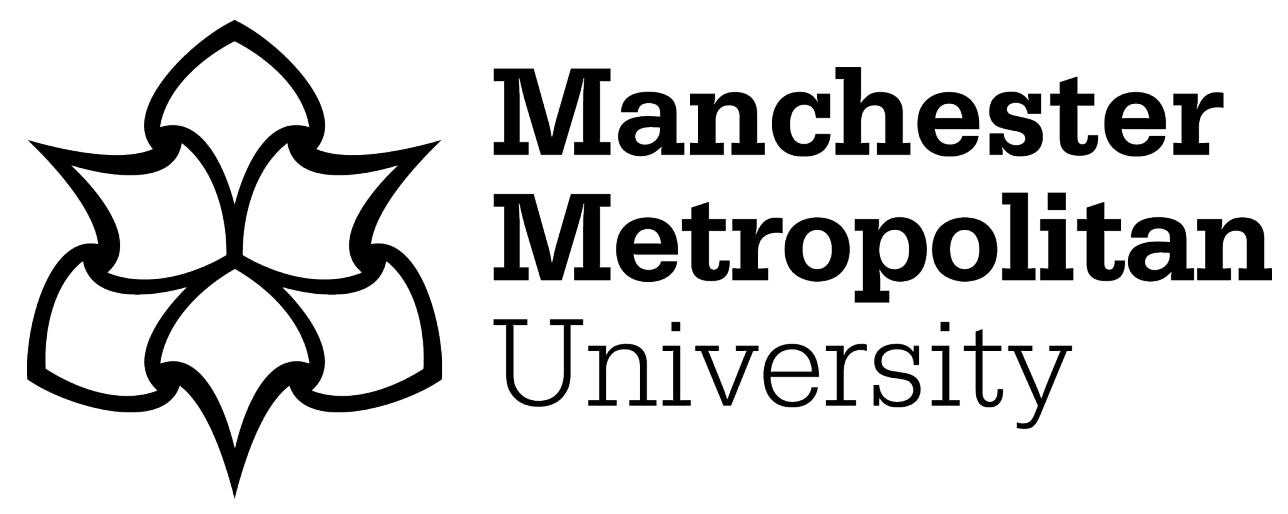

Hagan, Robert J (2019) Getting out of the house: the use of community transport as a third place for rural-dwelling older adults. Ageing and Society, 40 (11). pp. 2519-2539. ISSN 0144-686X

Downloaded from: https://e-space.mmu.ac.uk/623761/

Version: Accepted Version

Publisher: Cambridge University Press (CUP)

DOI: https://doi.org/10.1017/s0144686x19000722

Usage rights: Creative Commons: Attribution-Noncommercial-No Derivative Works 4.0

Please cite the published version 


\title{
Getting out of the house: the use of community transport as a third place for rural-dwelling older adults
}

\author{
Robert J. Hagan ${ }^{1}$ \\ ${ }^{1}$ School of Social Science and Public Policy, Keele University, Keele, Staffordshire, UK \\ Email r.j.hagan@keele.ac.uk
}

(Accepted 22 May 2019)

\begin{abstract}
Rural-dwelling older adults experience significant shrinkage in their social networks and capital due to transitions in later life related to poor physical health, mobility difficulties and bereavements. Being rurally located adds an extra layer of disadvantage. This article explores how older adults may use community transport systems to not only facilitate important social tasks but also maintain friendships and other valued relationships. Semi-structured interviews were carried out with 11 users of a rural transport community bus service in western Northern Ireland. The interviews identified that participants viewed the transport system as a highly valued conduit for helping escape isolation, maintaining autonomy, and providing an informal space for relationship building and accessing local news.
\end{abstract}

Keywords: community transport; autonomy; third place; social inclusion; social networks

\section{Introduction}

In later life, older adults' social networks increasingly become restricted due to the onset of losses, such as physical health declines (Steptoe et al., 2013; Burholt and Scharf, 2014), mobility problems (Rosso et al., 2013) and driving cessation (Siren and Hausten, 2015; Doebler, 2016). Whilst living in a rural area is sometimes romanticised (Walsh et al., 2012) and associated with better life satisfaction (Milbourne and Doheny, 2012; Oguz et al., 2013), older people who live rurally may encounter significant disadvantages in terms of social integration. For example, in rural areas, institutional disengagement occurs as venues commonly associated with rural social interactions, such as the local post office, convenience shops and pubs, are increasingly in decline and disappearing (Gray, 2004; Milbourne and Doheny, 2012; Shergold and Parkhurst, 2012; Walsh et al., 2012). The inability to access commonly used services and facilities that are recognised as vital for civic participation leads to some older rural dwellers becoming socially excluded and feeling anxious about becoming separated from mainstream society (Gray, 2004; Lucas, 2012; Walsh et al., 2017). 
Maintaining or increasing social engagement for older adults is beneficial for improvements in quality of life and cognition, and reductions in depression and mortality (Glass et al., 2006; Rosso et al., 2013). Being able to access services through adequate travel systems is a priority for older rural dwellers (Kamruzzaman and Hine, 2012). In Northern Ireland, 35 per cent of those over 60 have physical disabilities that make travelling more difficult (Department for Infrastructure, 2017) and the older one is, the more likely limitations to participation due to transport difficulties are reported (Shergold and Parkhurst, 2012). For rural dwellers, social integration in the United Kingdom (UK) and Ireland is increasingly dependent upon car ownership (Gray, 2004; Gray et al., 2006; Ahern and Hine, 2012; Milbourne and Doheny, 2012; Shergold et al., 2012; Smith et al., 2012; Walsh et al., 2012; Zeitler and Buys, 2015). By contrast, lack of access to a car in a rural area may be a measure of deprivation, with there being an additional need to explore the value of alternative means of transport for older people (Doebler, 2016). This article, then, asks participants using a rural community transport service in western Northern Ireland to reflect upon their experiences. The author will examine findings in light of two theoretical concepts: autonomy and ideas of a third place.

\section{Capital in rural areas}

Social capital relates to the ease with which individuals access appropriate support and resources from both their immediate social network and more peripheral sources (Halpern, 2005). Capital is distributed unequally across social stratifications and this leads to both individuals and communities being at risk of greater exclusion (Lucas, 2012). For those living in rural contexts, strong bonds leading to co-operation and access to assets are more likely to be located within family networks and immediate neighbourhoods (Sorensen, 2018), and rural communities are perceived as being more likely to contain these than urban contexts (Gray, 2004). Weak ties, however, are beneficial in connecting individuals to the outside world but these are dependent upon rural dwellers having the right connections and the skill, motivation and ability to activate these (Urry, 2012).

Rural communities are often comprised of both exogenous populations, those who live in one area but whose social ties and work may be primarily outside it, and endogenous ones, those who live and work in the same area with social ties largely related to that community (Terluin, 2003). Rural-dwelling older people may be more likely to be endogenous as 83 per cent of activities take place within 8 kilometres $(\mathrm{km})$ of an older person's home (Shergold and Parkhurst, 2012). Endogenous communities value ongoing social relations with other long-standing residents (Tregear and Cooper, 2016) but are only sustainable when the resources supplied meet the needs of those living therein; as such, they are dependent on various kinds of capital that can be reciprocated (Gray et al., 2006). Retaining these factors, whilst recognising the external benefits of weak links in wider networks in which the rural community is embedded, may be crucial for survival and growth (Terluin, 2003; Tregear and Cooper, 2016).

Capital is also dependent upon how individuals access networks due to the intersections of mobility impairment, age, gender, income and rural location in 
later life (Smith et al., 2012; Lucas et al., 2016). Motility capital, which relates to both the individual's capacity to be mobile and their opportunities for travelling (Shergold et al., 2012), is particularly relevant for older rural dwellers. Older people who are less mobile, have less income and also lack access to public or private transport are at greater risk of social impoverishment, isolation and exclusion (Farrington and Farrington, 2005; Gray et al., 2006; Lucas et al., 2016). Those living rurally experience a 'double jeopardy' with the disadvantages of being located at a distance from service providers being amplified when health and mobility problems occur in later life (Department of Health, Social Services and Public Safety Northern Ireland, 2014; Warburton et al., 2017).

Maintaining network ties may be dependent upon being able to negotiate 'complexities of travel' (Urry, 2012: 25). Mobility is the glue holding social communities together (Gray et al., 2006, after Urry, 2002), assisting with the promotion of emotional wellbeing and the fulfilment of social roles (Ziegler and Schwanen, 2011). Access to travel facilitates and sustains pleasurable and productive social contact (Urry, 2012) that provides older people with a sense of normality, independence and inclusion (Musselwhite and Haddad, 2010). Due to demographical changes either chosen or enforced, especially in relation to younger family members' migration, rural-dwelling older people may be more vulnerable to geographical exclusion (Lucas, 2012). The distance individuals travel to connect with members of their network has increased significantly in recent decades (Urry, 2012).

Ownership of a private car is noted as having a positive effect on the size and strength of social networks (Lucas, 2012) and in enabling access to out-of-home social activities (Banister and Bowling, 2004). Car ownership in rural areas generally has had a knock-on effect on the 'market' for public bus services, with declines observable since the 1950s (Farrington and Farrington, 2005), and therefore there is increased disadvantage to those rural dwellers who do not have access to, or cannot use, a car (Gray et al., 2006; Lucas, 2012). Decreasing health is a primary cause of driving cessation (Siren and Haustein, 2015; Dickerson et al., 2017) and those who have given up driving are more likely to rely on other means for essential trips and sacrifice those journeys that are more discretionary, and possibly more pleasurable (Burholt and Scharf, 2014). Driving cessation is also associated with lower income, less physical activity and fewer social activities (Anstey et al., 2006), and the consequences have been described as being similar to bereavement (Ziegler and Schwanen, 2011) or having a limb amputated (Davey, 2007). Non-drivers are more likely to be female (Dickerson et al., 2017), living alone, report poorer self-rated health, and have impairments in cognition, vision and hearing (Anstey et al., 2006). However, driving cessation may be more difficult for males, who are more likely to stay at home once they stop driving rather than use community transport schemes (Ahern and Hine, 2012). Older people's ability to avoid exclusion may be reliant on public transport services, but the provision for this in rural areas is often poor (Walsh et al., 2017) and accessing these services may be doubly impaired by having to navigate routes to bus stops without pavements or street lighting (Shergold et al., 2012). Additionally, buses have been reported to be a stigmatised form of transport (Green et al., 2014) and asking friends, neighbours or families for lifts may be viewed as an uncomfortable imposition (Shergold et al., 2012). 
Whether the state feels there is a requirement to intervene may be dependent upon views that those who choose to live in rural locations may not have a predetermined right for a state-funded service to provide them with access to resources (Farrington and Farrington, 2005). However, being able to move location is not just a matter of personal choice, especially when living in relatively impoverished rural areas, but may be reliant upon factors such as financial capacity, ability and social class (Urry, 2012).

\section{Autonomy}

The role of autonomy in promoting quality of life is under-researched (Boyle, 2008). Autonomy is described as individuals feeling free to make their own decisions as reflected by their own personal beliefs, ambitions and aims (Spicker, 1990; Doyal and Gough, 1991). Spicker outlines that it is distinct from selfdetermination as autonomous individuals have freedom to make decisions whilst those who are self-determining take action. The intention then to direct one's own chosen path without interference or external prompting is fundamental to acting autonomously (Chung et al., 2018). This includes being allowed to pursue a course of action that may be viewed by others as risky, unhelpful or harmful (Westlund, 2009; Kenealy et al., 2011; Carey, 2015). However, promoting individuals' autonomy to live fulfilling lives without arbitrary limitations being imposed is a hallmark of liberal democratic ideology, with the view that lives lived in ways of individuals' own choosing lead to better societal outcomes (Doyal and Gough, 1991; Sherwin and Winsby, 2011). As Doyal and Gough (1991: 184-185) say, 'To be denied the capacity for potentially successful social participation is to be denied one's humanity.'

Autonomy is at risk in later life when the older person's ability to direct their own choices is compromised by ill-health and dependency (Sherwin and Winsby, 2011). Impaired autonomy relates to an individual being constrained from carrying out actions (Doyal and Gough, 1991) and can be associated with institutionalisation and disability in later life. Therefore, maintaining independent living is beneficial for individuals' sense of control, self-determination and psychological health (Perrig-Chiello et al., 2006; Boyle, 2008). Whilst executional autonomy relates to the freedom individuals have to complete actions themselves, delegated authority refers to individuals declaring a choice that is then carried out by another on the individual's behalf (Leece and Peace, 2010). This becomes particularly important in later life (Boyle, 2008) as this allows the individual retention of authority over one's own circumstances and having choice over a range of viable options (Westlund, 2009; Doyal and Gough, 1991).

Whilst autonomy has been critiqued by feminist voices as (mis)representing the promotion of male goals (Barclay, 2000), the development of relational autonomy has been important in rejecting 'atomistic understandings of the self (Sherwin and Winsby, 2011: 185) and instead recognises that 'the self is socially determined' (Barclay, 2000: 54). Relational autonomy recognises that individual actions never exist in a vacuum or separated from culture but are affected by mutually dependent exchanges transferred in relationships with others (Mackenzie and Stoljar, 2000; Westlund, 2009). Actions, then, are undertaken not merely for one's own pleasure 
but take account of the impact and potential harm on wider networks, communities and others (Barclay, 2000; Christman, 2004).

\section{The third place}

The third place is a venue for social participation broader than the 'two-stop' notion of home and work (Oldenburg and Brissett, 1982). Third places are locations, such as coffee shops, where people gather with the primary focus of enjoying each other's company and where emotional bonds may be formed (Oldenburg and Brissett, 1982; Peters, 2016). They do not have to be 'necessarily interesting or notable' (Oldenburg and Brissett, 1982: 270) and are unpretentious places where interaction is encouraged, seating is comfortable, there is relaxation and acceptance, and the place feels owned by those in attendance (Rosenbaum et al., 2007; Pennington, 2017). As Tuan (2001: 6) notes, 'what begins as undifferentiated space becomes place as we get to know it better and endow it with some value'.

Locations are not constrained by the regimens of employment or even kin relations (Oldenburg and Brissett, 1982). Following retirement, third place relationships may be sustained or introduced when other working relationships are lost (Rosenbaum et al., 2007). Third places allow social support to be provided, not by one individual, who may feel burdened by the responsibility, but by a wider network of those who 'are in the same boat [or] ... have lived the same experiences' (Rosenbaum et al., 2007: 46). Relationships are not bound by obligations, rather valued information and updates are shared freely (Peters, 2016). Conversations are spontaneous and sociable, flow freely, are full of emotional expression and are not normally dominated by one individual (Oldenburg and Brissett, 1982; Peters, 2016). Third places are frequented as a way to avert emotional or social loneliness (Rosenbaum et al., 2007).

For older people, third places may become less accessible. Later-life losses such as illness, disability and bereavements (if partner was a car driver, for example) may lead to communities and social opportunities becoming less accessible (Goll et al., 2015). Older women particularly still report barriers to social participation due to their spouse dying or ceasing driving (Walker et al., 2013). Due to poor public transport links and the geographical dispersal of services, living rurally is a barrier to social engagement (Shergold et al., 2012; Walker et al., 2013). One-third of older people report that they would like to engage in more social activities than they do and barriers to this include the cost of travel and activity, inaccessibility of transport services, and difficulties boarding and leaving vehicles (Shergold et al., 2012; Mackett, 2015). Additionally, older people may wish to avoid third places that are new to them due to fears around rejection, not fitting in or even possible exploitation (Goll et al., 2015).

\section{Context}

Participants in the study live in rural areas of counties Derry/Londonderry and Tyrone, in a location generally referred to as being 'west of the Bann (river)', with participants being older individuals who use a community transport scheme in order to access resources, services, appointments and informal meetings. 
Using the typology of Smith et al. (2012), the participants live in a mix of rural locales, including villages (less sparse), hamlets and dispersed areas. Although living rurally, all participants were within ten miles of three urban centres, Derry (a city), Omagh (a town) and Strabane (a small town), and the transport service connects users with these larger centres for both shopping and other social activities. This area is one which, due to political and socio-religious reasons, there was ongoing lack of economic development following the partition of Ireland in the 1920s (Robinson, 1970) and therefore is regarded as more isolated than those dwelling rurally east of the Bann. The rural areas in which residents are living therefore may not be immediately attractive to incomers, though in recent years it has become increasingly common for individuals to commute to Derry, Omagh and further afield from these locations. The older adults in this study were more likely to be endogenous to their communities, with distinct cultures and histories valued. The informal social networks of rural communities in Northern Ireland retain great importance for individuals, who report they do not feel the necessity to belong to wider community groups (Heenan, 2010).

In Northern Ireland, those in rural areas travel nearly double the distance of those who live in urban centres, are more likely to use a car to do so and spend more time travelling to destinations (Department for Infrastructure, 2019). For those over 60, 73 per cent use a car as their main mode of transport (Office of First Minister and Deputy First Minister (OFMDFM), 2015), with 70 per cent of all journeys via the car (Department for Infrastructure, 2019). Whilst 88 per cent of older men in rural Northern Ireland hold a full driving licence, only 71 per cent of women do and older women are twice as likely to be a car passenger (Department for Infrastructure, 2019). However, between the ages of 80 and 85, one study reported a drop in car driving from 51 per cent of older adults to 15 per cent (Anstey et al., 2006). A previous study of the broader rural location near to the participants in this study found that 63 per cent of households where older people lived did not have access to a car (Nutley, 2005).

For rural-dwelling older adults in Northern Ireland, if one wished to forego the car, there are often few or no alternatives for those in rural areas to access desired resourcing. The provision of public transport from rural locations to urban centres in Northern Ireland is recognised as poor (Nutley, 2005; Heenan, 2006; Kamruzzaman and Hine, 2012). Public bus services in rural areas are heavily subsidised (Gray et al., 2006), limited, especially in terms of evening and weekend services (Parry et al., 2004; Ahern and Hine, 2012), and hard to access (Treacy et al., 2004). Less than 5 per cent of journeys undertaken by those aged over 60 in Northern Ireland (2009-2011) were via the public bus service (Locus/Age NI, 2014). Nine per cent of rural households in Northern Ireland have at least a 44-minute walk to their nearest bus stop and two-fifths of rural residents do not know the frequency of local buses (Department for Infrastructure, 2019). Whilst 84 per cent of households are within $1.5 \mathrm{~km}$ of a bus stop, Nutley (2001) indicates that even if bus stops are within walking distance, mobility barriers in later life may render these inaccessible. Physical disability causes 36 per cent of adults over 60 in Northern Ireland to experience difficulties with travel (Department for Infrastructure, 2019). 


\section{Community transport}

Community transport is a service developed by voluntary or other third-sector organisations to meet specific needs in a particular area, particularly individuals who either do not own or have access to a car and struggle to make regular trips by existing public transport (Nutley, 2001). The UK Government recognises the service as being beneficial for those who struggle to make journeys on their own, particularly older citizens, and is especially valuable in remote rural areas (House of Commons Transport Committee, 2017). Community transport is an example of flexible or demand-responsive transport, defined as services with an adaptable approach to picking up passengers from their homes and delivering them to specific destinations, during service hours and on service days, and with variable approaches to payment and passenger category (Brake et al., 2007; Shergold and Parkhurst, 2012; Davison et al., 2014). Customers must ring in advance to book the service (Brake et al., 2007). Destinations include shopping, meetings, appointments and excursions (Nutley, 2001). Although it has been advocated that extra funding is required for rural dwellers in order to be equitable in terms of 'rural proofing' (Age UK, 2013), funding for supporting services, such as community transport, is at risk (Fergus, 2016).

The community transport scheme under discussion in this article formed in March 2012, amalgamating two smaller rural transport schemes, and serves the rural areas of the Derry City and Strabane, and Omagh District Council areas. The organisation's primary aim is to provide transport for rural dwellers (not just older people) who have difficulty with or are unable to access transport. The service uses both buses and volunteer car drivers. Whilst the individual car-driving service can be more flexible, facilitating trips in the evenings and weekends, the bus runs a 'dial-a-lift' service between $8 \mathrm{am}$ and $6 \mathrm{pm}$, Mondays to Fridays. ${ }^{1}$ The dial-a-bus service provides nearly 20,000 unique trips each year, with nearly 15,000 trips completed by older adults. ${ }^{2}$ Of those using the service, 54 per cent are over the age of 65 and females make up 75 per cent of those using the service. ${ }^{3}$ The scheme is under pressure to deliver the service at the lowest cost possible and, like other community transport providers in Northern Ireland, faces cutbacks (Committee for Regional Development, 2013; Fergus, 2016). Services are for individuals or groups who may decide to enter town together for shopping or social needs. It is this latter category that is of particular interest in this study.

Community transport services for social activities are not unusual. A survey of services in England found that operators commonly provided trips to social outings and community activities as well as health-related trips for older passengers (Shortland et al., 2014). For the scheme under analysis, approximately 62 per cent of trips are for social activities, personal business or shopping. By contrast, less than 6 per cent are for health appointments and 25 per cent to access formal day service provision. ${ }^{4}$

\section{Method}

The dial-a-lift rural community bus service is the focus for this study. Qualitative semi-structured interviews were conducted with 11 older adults (age range 62-87, with eight aged 80 or above; see Table 1) who used this service in counties Derry/ 
Table 1. Profile of interviewees

\begin{tabular}{lll}
\hline Name (pseudonym) & Age & Approximate time using service \\
\hline Aoife & 86 & 8 years \\
\hline Barbara & 87 & 8 years \\
\hline Colleen & 73 & 4 years \\
\hline Deirdre & 77 & 12 years \\
\hline Edith & 83 & 12 years \\
\hline Frances & 80 & 14 years \\
\hline Gina & 83 & 2 years \\
\hline Holly & 87 & 3 years \\
\hline Ingrid & 87 & 1 month \\
\hline Jasmine & 86 & 6 months \\
\hline Kyle & 62 & 18 months \\
\hline
\end{tabular}

Londonderry and Tyrone. Interviews were carried out by the researcher at the operational bases of the community transport service in either Strabane or Omagh, with participants being bussed to these venues to participate. A range of questions had been pre-prepared for the interviewees, though these acted merely as prompts and the interviewer frequently moved away from questions to prioritise issues that interviewees wished to discuss. The interviewees comprised ten females and one male.

Participants received an information sheet that detailed the project and its purposes. This included permission to end the interview at any time, should they so wish, without the need to supply a reason for this. Participants then signed consent forms and were assured that personal information would be kept confidential. Ulster University's Research Ethics Committee granted ethical permission for the study (reference REC/16/0094).

A grounded theory approach was used to develop themes from the interviews. Initial coding was carried out in order to categorise interview transcriptions line by line. This axial coding led to the combining of the initial categories into the themes and sub-themes that comprise the Findings section below.

\section{Findings}

Three themes emerged from the data:

- Escaping isolation, loss and loneliness.

- Being able to execute autonomy.

- Making connections on the bus.

\section{Escaping isolation, loss and loneliness}

This theme captured reasons articulated by participants about the necessity of using the community transport service. These respondents were conscious about the 
comparative isolation of rural living. Some lived in small, detached dwellings with no immediate neighbours:

There's nobody in any of the houses. Now guest houses, plenty of people but she's away in the day time and the one above me is, I can't mind the people's names, and they're both working too. You're just a kinda on your own. (Holly)

It's only a country area. The road that I live on there's about two, four, seven or eight houses along the road and that's it and they're all out at work all day. (Gina)

Others were conscious about the inefficiency or inaccessibility of existing public services for meeting their needs due to the dangers of rural roads without pedestrianised walking routes:

The bus stop, which is, the nearest one is just over a mile away and you have to get to it by walking beside a busy road, [name of road] and I, it was just too dangerous because you get quarry traffic, big trucks and the slipstream, you could get drawn underneath. And the next bus stop then which is just over a mile and a half away is, you get to it by walking over the fields and down muddy lanes. (Kyle)

The road's very dangerous now, too ... I haven't walked them roads this year. It's ... big lorries and everything ... There's a lot of accidents on the road too. (Deirdre)

Losses associated with later life had an impact on the ability of participants to move freely and do what they wanted. Some had to stop driving due to health issues:

My eyesight's not good enough, I would just see about from here to the end of the table if I concentrate. I've got peripheral vision. It's macular degeneration. It's very annoying ... I really miss my car ... I lived in my car. I was always on the hop going somewhere ... I used it all the time. I was very lazy. (Gina)

I was driving a small car ... Then I had the stroke. The first stroke. And ... I was no longer available to do the [gardening...] And, so, I don't know, there's that and there's guilt and other things all combined to bring on probably the worst black depression, well, I've ever experienced. And it got to a serious stage where I just - didn't think it was worth carrying on. (Kyle)

Bereavement was a difficult transition that impacted respondents' social lives:

I would feel lonely I think nearly all the time. Not used to living alone. (Jasmine)

Well, I went into a wee corner and I didn't want to come out after [husband] died. It was just, a near breakdown, so I had, because I was so busy with him ... Just was in the home and didn't want to go outside the home. I was just ... it was a burden to me to go out to do a bit of shopping ... I wouldn't have even bothered and I didn't really need anything in the house because I wasn't eating proper. (Colleen)

[My husband] died 12 years past there in February ... That was lonely ... I had neighbours and if they didnae see your blinds open, they'd be coming knocking to see what was wrong, is there anything wrong with ye? You know? But just 
sometimes ... when you're left on your own, you just didnae want to see, you don't want to be bothered, you don't want to see anybody. (Edith)

Others recognised the benefits of social engagement following bereavement:

Since my husband died, I do not [feel lonely]. I thought I didn't at the beginning, I says, how will I manage? But I go out and talk away to people and it keeps the ... keeps your mind open. (Frances)

I felt ... lonelier now than ever since my son died. I never felt the same. You know, you lose a wee bit of interest in life, you know ... This getting out helps me now, you'd be talking to people and you sort of forget about yourself. (Deirdre)

Becoming aware of the community transport service allowed participants to avail themselves of opportunities for social activities and shopping:

A lady come with a form and asked me would I be interested in going shopping a few days. I was lonely at home and I'd lost my husband and I was just not at myself. And this lady come and asked me about the forms, she brought me the forms and I filled it in and I didn't look back because it is very interesting because the ladies that's on the bus is great fun. (Colleen)

Word of mouth, that's when I would have heard it, by word of mouth and then you would have filled in a form and had me bus pass and all. (Deirdre)

\section{Being able to execute autonomy}

The community transport service enabled participants to maintain or retain some level of independence, a concept respondents valued:

Aye, I'm very independent. You know, why didn't you ask me? Why didn't you ask me? No. If I can do it myself, I do ... 'cause I'm able enough. (Edith)

I'm very happy to be able to go out. I see people ... not able to go out. No, I'm very happy, at my age that I'm fit to go. I thank God every day for being able to get up and go. (Frances)

The choice available to service users through directly visiting shops was valued:

There are ways now like Asda and them places, if you sent an order to them ... but you like to be there to see the things, don't you? And Iceland has, ah, if you buy so much you can get delivered but you like to be there to pick your own things, don't you? ... You know, there are different things each week. Then there'd be an odd wee bargain too you can pick up, you see. (Deirdre)

As well as executional autonomy, the community transport service allowed participants to delegate more difficult shopping tasks to bus drivers, a service which they would not have been able to use on public transport:

The drivers will come to the door for you, carry your bags back in again when they're full ... [Without the service] I would have to go down to the village just 
and pay there for groceries and I wouldn't get them left home for me. I'd only have to go and buy a small amount that I could carry. (Aoife)

Usually you go in the bus to Strabane to go to Asda and then if you've done a bit of shopping, they come back for you at 12, then they give you an hour up the town so then if you've to do some early shopping, you can put it on the bus, so it's very handy. You can't do that on Ulsterbus ... If you had anything heavy, you don't usually get it until near the bus time, the way you work it. (Deirdre)

The service also allowed participation in desired social activities or to check in with loved ones:

I've been able to go into the swimming. And what else do I do? Oh, ah, [community transport] takes us to the community centre and all the walks and things that they go on ... There's something on there nearly every day. (Aoife)

Then I do go to see my son who, who has bipolar depression. He lives by himself and they take me in to see him. (Gina)

Even for participants who still drove, being able to avail of the community transport service took away anxieties of having to access built-up areas or difficult routes:

I don't like driving in built-up areas. I avoid driving. I just would drive short distances where I'm not ... having to cope with a lot of traffic. And, ah, as you know, in the town there is very little parking space so you're coping with traffic all the time ... I live in the country so I drive to places in the country which is maybe only about a mile and a half away or something like that ... But I don't enjoy driving now ... because of the amount of traffic. I like to just cope with a small amount of traffic. So I avoid towns. (Jasmine)

I go to a chiropodist away out at the ... hospital and it would be great if I could get the bus to go there because there's quite a few roundabouts. When you get older, you're not as good at the driving so I would love to keep [the community transport]. (Ingrid)

Participants also revealed that their use of the service took account of the needs of others. It was important to some respondents that they felt they were not 'putting others out':

You know, where if you were going to drop me off at an awkward place for your big bus and come past this small car, look, I will choose which is more convenient to them 'cause I will fit in ... I mean, that is my attitude. That, ah, I appreciate the service so much and, ah, I'm so grateful for it. (Jasmine)

To start off with it was on my own but I, I said, look, it seems like a waste of money. Can we alter the times so I fit in on a regular lift? They said, sure. (Kyle)

The mobility of interviewees varied and, whether frail or not, the community transport service gave them the opportunity to leave the house.

When I bang that front door after me, I feel a different person ... Once I get out and bangs the door after me, I'm down the street, I feel ... that much difference ... 
I'd just be that glad that I'm able to get out and away. (Aoife)

If it wasn't for the wee bus, we call it the wee bus ... I wouldn't be out ... If it wasn't for them, I wouldn't be out. I wouldn't be out. (Edith)

See, if you're in the house, you'd be ... I would get down at times, depressed, I would. I definitely do. A lot, you know. But when you're out then that gives you a wee lift. (Deirdre)

You feel you're getting out ... Very important that. (Barbara)

Additionally, whilst for some visitors to the home were welcomed, there was also a sense that they could be intrusive and unchosen:

I'm not sure now I enjoy company for people coming in to me or not 'cause I knit. I get into the big chair and I light a fire at night and I knit and watch the TV. I like to be on ... my own sometimes. (Edith)

\section{Making connections on the bus}

Whilst service users had purposeful reasons for using community transport, such as the weekly shop or being taken to a particular social activity, respondents' narratives revealed that the journey itself had its own specific values. The buses themselves became places where individuals became acquainted or reacquainted:

Well, you might have knew one or two of them but the rest was strangers to us but once they got on, we got to know one another and we're all like a wee happy family now, that's what we're like ... We all chat together. It's just like everybody knows, like brothers and sisters. Aye, no, we're all very friendly. (Edith)

You knew them. I would have gone to school with them. You did ... You'd have school pals. You'd have met some of them that was going on the bus too ... Times you wouldn't have seen them because, see I would have been away working, never would have been so much out socialising with them and then we started on the bus ... Some of them had been away in England or Scotland and had come home and, funny, you'd meet up with them and have a great time. (Frances)

The bus that we're on is like a family affair because everybody knows each other and they look out for each other ... You'd kind of - just was one of the group ... That was like a group that you were in with and you didn't know whether you fitted in with them or not. But then everybody was that good and then you fitted in. It was like a jigsaw. Missing link. (Colleen)

Familiarity on the bus extended to where travellers usually sat:

There's a girl comes from Drumahoe and ... we all have our own seats now for we're that long going and I sit behind the driver, you know ... She sits behind me and she's a very nice person. She's a bit older than me and she's a very nice person. (Barbara)

Respondents reflected on how the informal bus chatter and engagement had a positive impact on mental health: 
You're talking to people about other different things. It lifts your mind. It does. It lifts your mind, it does. See, if you're in the house, you'd be ... I would get down at times, depressed, I would. I definitely do. A lot, you know, you know. But when you're out then that gives you a wee lift and ... even going [on] that wee bus there, you'd be talking to the passengers. (Deirdre)

I meet a wide range of people and they're really cheerful. And the thing is, they, some of them are even worse off than I am ... But they, when I get on the bus, 'Oh, Kyle, Kyle.' You know, it makes you feel good that these people know my name. (Kyle)

The bus acted as a news outlet so that service users could catch up on events in small townlands and rural districts that were meaningful and important to them:

[We talk about] family affairs and what's happening round Castlederg and what's new because she would know what's from Castlederg and I wouldn't ... I would know some about Newtownstewart. And the other lady on the Friday is from Sparmount so I get some news from that direction. (Colleen)

$\mathrm{Oh}$, we talk about everything. Were you such a here, were you there, did you see so and so and all this. You know, and was there anybody sick and we arrange to go maybe to see them and that type of thing. We had two funerals there, you know, we were arranging to go to them. Two wakes, so we do a lot of wakes round here. (Frances)

Reminiscing was also valued:

One conversation leads to another. And maybe the past, usually something comes up with the past ... Something always comes up [about] what we did at school and that's the way we would go on. (Edith)

\section{Discussion}

The study presented here has outlined how a rural community transport service is highly valued by those who use it. Participants use the services for a variety of reasons, including shopping, personal visitations and business, and social activities and groups. They appreciate the flexibility of the service. More importantly, in terms of this article, respondents have identified that their reason for using the service both enables autonomy and personal choice, and also provides access to an informal social space that allows enjoyable interaction and local news updates.

\section{Autonomy}

Firstly, the very idea of being able to leave home and access a separate space where interactions take place appears to be chosen and therefore supportive of autonomy. Older people do not wish to have their lives exclusively revolve around the four walls of their own home as this may be detrimental for individuals' mental health. Poor physical health, losing contact with family and friends, bereavement and living alone are all identified as potential triggers for depression in later life (Allen et al., 2014). By contrast, direct face-to-face contact, especially with friends, is valued for 
expanding social capital and adding years to individuals' lives (Urry, 2012; Uvnas Moberg, 2013) and participation outside the home enriches life and leads to new experience, allowing opportunities to contribute and be socially involved (Fristedt et al., 2011).

Age UK estimates that approximately one in ten older people feel trapped in their own home and that around 600,000 older people in the UK only leave the house once a week (Davidson and Rossall, 2015). Additionally, there is not strong evidence for benefits of house visitations for alleviating individuals' loneliness and social isolation (Cattan et al., 2005). In one study with those who are disabled or with a mobility limitation, the opportunity to engage socially outside the house was not only more beneficial in comparison with those with unimpaired mobility but was more valuable than holding social engagements in one's own home (Rosso et al., 2013). In other words, the experience of impaired mobility may lead to a greater appreciation of opportunities for social engagement outside the home. Encouraging out-of-home activities for those who feel more confined to these contexts, then, may yield not only greater social rewards but benefits for mental and physical health.

Autonomy relates to choice and the freedom to access preferred lifestyle activities (Stevens et al., 2011). Being able to make informed choices about one's own services and resources is respectful and promotes older adults' agency (Boyle, 2008). In Northern Ireland, whilst 55 per cent of older adults participate in at least one social activity, only one in ten participate in groups focused solely for older people (Devine and Montgomery, 2017). It has been hypothesisesd that only social activities that are chosen and meaningful will be those of value to older adults (McPherson, cited by Rozanova et al., 2012). For rural-dwelling older adults without their own transport, certain limitations impinge upon desired activities, including accessibility, cost and opportunity (Rozanova et al., 2012). Formal services provided by health and social care are felt to be inappropriate and not reflective of rural dwellers' wishes (Heenan, 2006). By contrast, the rural community transport service may promote choice by providing an equitable service for those who may be at risk of social exclusion (Stevens et al., 2011). The community transport service not only permits older people to exercise executional autonomy by, for example, being able to make impulsive choices in shops and cafes, and visiting family, but also delegated autonomy, by being able to access readily available, appropriate support, such as help lifting groceries on and off the bus. It can also assist with the difficult transition that older drivers make as they make decisions to reduce their driving or choose only certain times or routes for driving (Dickerson et al., 2017), an issue apparent for some of the sample interviewed. Budget cuts and restrictions threatening community transport services are not only threats to health and socialisation but also to autonomy, especially for those less well off (Boyle, 2008). In later life, women are more vulnerable to deficits in functional autonomy than men (Perrig-Chiello et al., 2006) and, for the women in this sample, the scheme is able to help facilitate their own decision making and choices in socialisation and shopping.

The use of community transport services could be viewed as stigmatising, with passengers seen as those being especially in need or less able (Shergold and Parkhurst, 2012). These authors note a perceived negative impact on autonomy 
may be individuals using the service having to fit in with service providers' timetables, especially regarding shopping runs that often operate on fixed mornings. However, there is evidence, stated in the findings, of participants feeling willing to compromise to fit in with this and this reflects relational autonomy and being considerate of the needs of others, whilst availing of the service. Relational autonomy was also clearly evidenced in bus interactions, where there were opportunities for respectful relationships, with some evidence of reliance and reciprocal exchange (Barclay, 2000; Sherwin and Winsby, 2011). Tailored transport services can facilitate the 'potential for movement' (Ziegler and Schwanen, 2011: 760) that promotes older people's freedom and autonomy.

\section{The third place}

Transport services are often seen to exist to meet a 'derived demand' (Ziegler and Schwanen, 2011: 761), that is, they enable individuals to move from one location to another for a specific purpose to meet needs or wants. This study has proposed that the journey offers another specific role outside this functional need. When Oldenburg and Brissett (1982: 266) conceptualised the third place as a space where one can 'get away from it all' or escape, the writers had, intentionally or not, conceived a valuable theme for older adults - the need and benefits of being able to 'get out of the house'. Older men and women have been found to prefer different types of social activities in later life: with women prioritising opportunities for emotional and instrumental help whilst men wish to focus on tasks that can be completed 'side by side' with others (Rozanova et al., 2012).

As such, it is perhaps not surprising that, for female participants in particular, the bus acted as a venue for socialisation in a way not anticipated when commencing the service. As the third place was initially conceptualised as citing the value of a chosen venue that is neither home nor work, it may be perceived that these become less important for older people who have retired. However, individuals using the service cite specific reasons and purposes for journeys and, thus, the concept still holds true, as suggested in Figure 1. Here the separation is from tasks that require carrying out, such as shopping or personal business (second place) and the informal social activities that are chosen and may be reducing due to mobility difficulties in later life (third place). In this conceptualisation, it is not difficult to see how the community transport used in this study, where friendships are maintained and news updates are received, can be evidenced as a third place. As Urry (2012: 26) states, 'Co-present talk is crucially embodied and involves ... a shared physical place ... Travel is thus about being co-present with significant faces'.

Reporting on public transport use in London, Green et al. (2014: 480) argue that bus usage for older adults facilitates 'opportunistic interaction', with the bus being a safe space 'to engage strangers in conversation'. Bus journeys are places of shared experiences, allowing exchanges on matters both noteworthy and inconsequential, helping to build a sense of community, as well as identifying social changes. The bus allows its passengers to have a sense of being in the world and part of that world' (Green et al., 2014: 488). This then becomes amplified and more especially valuable when journeys become regular events, such as those undertaken by the service users in this study. 


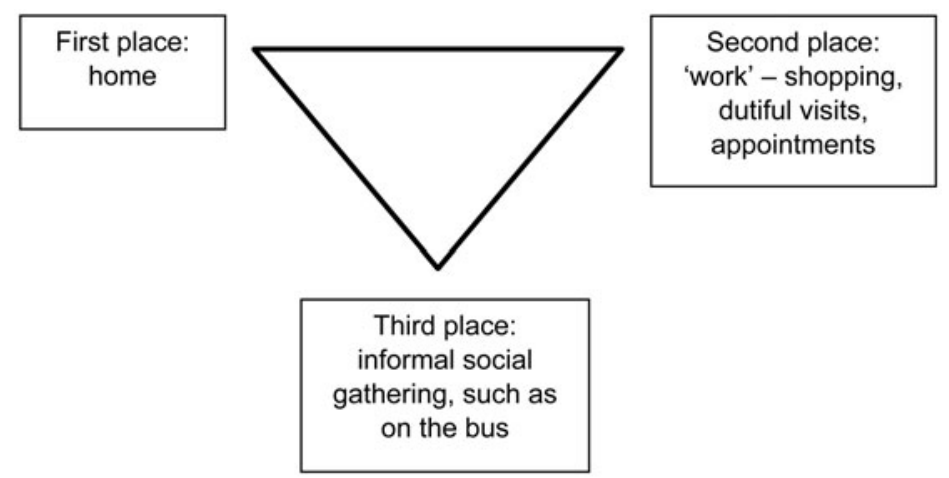

Figure 1. Conceptualising the third place in post-retirement life.

This venue as a third place may be particularly valuable for those whose life is becoming more restricted due to later-life transitions, such as poorer health and mobility, and bereavement. The study by Rosenbaum et al. (2007) of informal coffee shop relationships found that those who had negotiated a transition, such as divorce or bereavement, were more likely to maintain a third place relationship and, the more traumatic the event experienced, the greater the likelihood the individual would regard these relationships as important, meaningful and supportive. The support found in these relationships compensated for that which respondents felt they should have received from family members or co-workers.

\section{Environmental benefits}

Community transport has been identified as being the most responsive solution to the needs of 'doubly disadvantaged' older rural dwellers (Nutley, 2005). It should also be recognised that this state of affairs is apparent not only due to personal misfortunes but to a structural disregard of the needs and increasing isolation of rural communities, who cannot avail of their own private transport (Walsh et al., 2017). One impact of the Beeching report in England was the closing of many of the rail links in the area under discussion in the 1960s, leading eventually to County Tyrone being deprived of any rail travel whatsoever. It has been estimated that the dependency upon private cars is more pronounced in Northern Ireland than any other UK region (Cooper et al., 2001). Indeed, access to adequate transport in Northern Ireland has been recognised as part of a strategic objective in ensuring older people avail of services within the policy directive, 'Ageing in an Inclusive Society' (OFMDFM, 2006). The over-reliance on private car transportation in Northern Ireland is not only a social difficulty for older rural dwellers who cease driving, but an environmental disaster generally. Road transport produces approximately 28 per cent of carbon dioxide emissions in the UK yet there is a commitment to a 44 per cent reduction in greenhouses gases by 2030 (Kamruzzaman et al., 2015). The use of the car as a lifeline in rural Northern Ireland may be viewed as highly problematic within this context and yet there appears little incentive to offer realistic alternatives in this region - in one study, 
access to a car was the over-riding mediating factor between rural living and social inclusion (Shergold and Parkhurst, 2012). An increase in the use of community transport may assist in this but instead the regional government wishes to make cuts to this service (Committee for Regional Development, 2013; Fergus, 2016).

\section{Limitations}

The sample participating in this survey relates to a small geographical rural region in the western half of Northern Ireland and so it is difficult to generalise these findings with certainty to other contexts. Whilst the service is used by more women than men, the inclusion of only one male in the sample may lead to underreporting of reasons why males may choose community transport services. This reflects other research that states that older women are four times more likely to use public transport in Ireland than older men in Ireland (Ahern and Hine, 2012) and that males might be less likely to be aware of social opportunities or how to access these (Goll et al., 2015). It may be that the third place benefits indicated above are particularly important for female passengers, some of whom remarked that men were more reluctant to use the service; stated reasons included feeling more difficult about giving up their own driving and not wishing to go shopping. These opinions could be validated by exploration of the voices of older males who use community transport services and perhaps more specific research into this service user group could be developed in the future.

\section{Conclusion}

This study has highlighted that the purposes of using community transport services for rural-dwelling older adults are not just beneficial for functional and practical reasons such as facilitating shopping and appointments, but are highly important in facilitating autonomous thinking and allowing older people some control over their social lives. A community transport service has also become an unlikely social venue in and of itself, conceptualised in this article as a third place, where the informal and unprompted interactions of passengers add value and a feeling of being included in the small worlds of rural communities. Both these benefits are important in supporting continued independence and helping stave off institutionalisation in later life, and, in an age of personalisation, they allow older adults to choose their avenues for social participation rather than rely only on imposed services.

Conflict of interest. The author declares no conflicts of interest.

Ethical standards. Ethical permission for the study was granted by Ulster University's Research Ethics Committee (reference REC/16/0094).

\section{Notes}

1 Private email correspondence with Chief Executive of the scheme.

2 Scheme's own statistical returns to the Department for Infrastructure, 2017-2018.

3 See Note 2.

4 See Note 2. 


\section{References}

Age UK (2013) Later Life in Rural England. London: Age UK.

Ahern A and Hine J (2012) Rural transport: valuing the mobility of older people. Research in Transportation Economics 34, 27-34.

Allen J, Balfour R, Bell R and Marmot M (2014) Social determinants of mental health. International Review of Psychiatry 26, 392-407.

Anstey KJ, Windsor TD, Luszcz MA and Andrews GR (2006) Predicting driving cessation over 5 years in older adults: psychological well-being and cognitive competence are stronger predictors than physical health. Journal of the American Geriatrics Society 54, 121-126.

Banister D and Bowling A (2004) Quality of life for the elderly: the transport dimension. Transport Policy 11, 105-115.

Barclay L (2000) Autonomy and the social self. In Mackenzie C and Stoljar N (eds), Relational Autonomy: Feminist Perspectives on Autonomy, Agency and the Social Self. Oxford: Oxford University Press, pp. 52-71.

Boyle G (2008) Autonomy in long-term care: a need, a right or a luxury? Disability and Society 23, 299-310.

Brake J, Mulley C, Nelson JD and Wright S (2007) Key lessons learned from recent experience with flexible transport services. Transport Policy 14, 458-466.

Burholt V and Scharf T (2014) Poor health and loneliness in later life: the role of depressive symptoms, social resources, and rural environments. Journals of Gerontology: Psychological Sciences and Social Sciences 69B, 311-324.

Carey M (2015) Journey's end? From residual service to newer forms of pathology, risk aversion and abandonment in social work with older people. Journal of Social Work 16, 344-361.

Cattan M, White M, Bond J and Learmouth A (2005) Preventing social isolation and loneliness among older people: a systematic review of health promotion interventions. Ageing \& Society 25, 41-67.

Christman J (2004) Relational autonomy, liberal individualism, and the social constitution of selves. Philosophical Studies 117, 143-164.

Chung PK, Zhang CQ, Liu JD, Chan DKC, Si G and Hagger MS (2018) The process by which perceived autonomy support predicts motivation, intention, and behavior for seasonal influenza prevention in Hong Kong older adults. BMC Public Health 18, 65.

Committee for Regional Development (2013) Inquiry into the better use of public and community sector funds for the delivery of bus transport in Northern Ireland. Hansard. Available at http://www.niassembly. gov.uk/assembly-business/official-report/committee-minutes-of-evidence/session-2012-2013/january-2013/ inquiry-into-the-better-use-of-public-and-community-sector-funds-for-the-delivery-of-bus-transport-innorthern-ireland-easilink-community-transport-briefing/.

Cooper J, Ryley T and Smyth A (2001) Contemporary lifestyles and the implications for sustainable development policy: lessons from the UK's most car dependent city, Belfast. Cities 18, 103-113.

Davey JA (2007) Older people and transport: coping without a car. Ageing \& Society 27, 49-65.

Davidson S and Rossall P (2015) Evidence Review: Loneliness in Later Life. London: Age UK.

Davison L, Enoch M, Ryley T, Quddus M and Wang C (2014) A survey of demand responsive transport in Great Britain. Transport Policy 31, 47-54.

Department for Infrastructure (2017) Travel Survey for Northern Ireland In-depth Report, 2014-16. Belfast: Northern Ireland Statistics and Research Agency.

Department for Infrastructure (2019) Travel Survey for Northern Ireland In-depth Report, 2015-17. Belfast: Northern Ireland Statistics and Research Agency.

Department of Health, Social Services and Public Safety Northern Ireland (DHSSPSNI) (2014) Making Life Better: A Whole System Strategic Framework for Public Health. Belfast: DHSSPSNI.

Devine P and Montgomery L (2017) Social engagement of older people. In Cruise S and Kee F (eds), Early Key Findings from a Study of Older People in Northern Ireland: The NICOLA Study. Belfast: Queen's University Belfast/Northern Ireland Cohort from the Longitudinal Study of Ageing, pp. 46-55.

Dickerson AE, Molnar LJ, Bedard M, Eby DW, Berg-Weger M, Choi M, Grigg J, Horowitz A, Meuser T, Myers A, O'Connor M and Silverstein NM (2017) Transportation and aging: an update research agenda to advance safe mobility among older adults transitioning from driving to non-driving. The Gerontologist 59, 215-221. 
Doebler S (2016) Access to a car and the self-reported health and mental health of people aged 65 and older in Northern Ireland. Research on Aging 38, 453-476.

Doyal L and Gough I (1991) A Theory of Human Need. Basingstoke, UK: Macmillan Education.

Farrington J and Farrington C (2005) Rural accessibility, social inclusion and social justice: towards conceptualisation. Journal of Transport Geography 13, 1-12.

Fergus L (2016) Stormont threat to transport lifeline for rural communities. thedetail. Available at http:// www.thedetail.tv/articles/transport-at-the-heart-of-the-community-provides-more-than-200-000-trips.

Fristedt S, Björklund A, Wretstrand A and Falkmer T (2011) Continuing mobility and occupational participation outside the home in old age is an act of negotiation. Activities, Adaptation and Aging 35, 275-297.

Glass TA, Mendes de Leon CF, Bassuk SS and Berkman LF (2006) Social engagement and depressive symptoms in late life. Journal of Aging and Health 18, 604-628.

Goll JC, Charlesworth G, Scior K and Stott J (2015) Barriers to social participation among lonely older adults: the influence of social fears and identity. PLOS ONE 10, e0116664.

Gray D (2004) Rural transport and social exclusion: developing a rural transport typology. Built Environment 30, 172-181.

Gray D, Shaw J, and Farrington J (2006) Community transport, social capital and social exclusion in rural areas. Area 38, 89-98.

Green J, Jones A and Roberts H (2014) More than A to B: the role of free bus travel for the mobility and wellbeing of older citizens in London. Ageing \& Society 34, 472-494.

Halpern D (2005) Social Capital. Cambridge: Polity Press.

Heenan D (2006) The factors influencing access to health and social care in the farming communities of County Down, Northern Ireland. Ageing \& Society 26, 373-391.

Heenan D (2010) Social capital and older people in farming communities. Journal of Aging Studies 24, 40-46.

House of Commons Transport Committee (2017) Community Transport and the Department for Transport's Proposed Consultation. Available at https:/publications.parliament.uk/pa/cm201719/ cmselect/cmtrans/480/480.pdf.

Kamruzzaman M and Hine J (2012) Analysis of rural activity spaces and transport disadvantage using a multi-method approach. Transport Policy 19, 105-120.

Kamruzzaman M, Hine J and Yigitcanlar T (2015) Investigating the link between carbon dioxide emissions and transport-related social exclusion in rural Northern Ireland. International Journal of Environmental Science and Technology 12, 3463-3478.

Kenealy T, Goodyear-Smith F, Wells S, Arroll B, Jackson R and Horsburgh M (2011) Patient preference for autonomy: does it change as risk rises? Family Practice 28, 541-544.

Leece J and Peace S (2010) Developing new understandings of independence and autonomy in the personalised relationship. British Journal of Social Work 40, 1847-1865.

Locus/Age NI (2014) Age-friendly Belfast: Baseline Report. Belfast: Belfast Healthy Ageing Strategic Partnership.

Lucas K (2012) Transport and social exclusion: where are we now? Transport Policy 20, 105-113.

Lucas K, Mattioli G, Verlinghieri E and Guzman A (2016) Transport poverty and its adverse social consequences. Proceedings of the Institution of Civil Engineers - Transport 169, 353-365.

Mackenzie C and Stoljar N (2000) Autonomy reconfigured. In Mackenzie C and Stoljar N (eds), Relational Autonomy: Feminist Perspectives on Autonomy, Agency and the Social Self. Oxford: Oxford University Press, pp. 3-34.

Mackett R (2015) Improving accessibility for older people: investing in a valuable asset. Journal of Transport and Health 2, 5-13.

Milbourne P and Doheny S (2012) Older people and poverty in rural Britain: material hardships, cultural denials and social inclusions. Journal of Rural Studies 28, 389-397.

Musselwhite C and Haddad H (2010) Mobility, accessibility and quality of later life. Quality in Ageing and Older Adults 11, 25-37.

Nutley S (2001) Community transport in Northern Ireland: a policy review. Irish Geography 34, 50-68.

Nutley S (2005) Monitoring rural travel behaviour: a longitudinal study in Northern Ireland 1979-2001. Journal of Transport Geography 13, 247-263.

Office of First Minister and Deputy First Minister (OFMDFM) (2006) Ageing in an Inclusive Society. Belfast: OFMDFM. 
Office of First Minister and Deputy First Minister (OFMDFM) (2015) A Profile of Older People in Northern Ireland; 2015 Update. Belfast: OFMDFM/Northern Ireland Research and Statistics Agency.

Oguz S, Merad S and Snape D (2013) Measuring National Well-being: What Matters Most to Personal Well-being? Newport, UK: Office for National Statistics.

Oldenburg R and Brissett D (1982) The third place. Qualitative Sociology 5, 265-284.

Parry J, Vegeris S, Hudson M, Barnes $\mathbf{H}$ and Taylor R (2004) Independent Living in Later Life (Research Report No. 216). Leeds, UK: Department for Work and Pensions.

Pennington TM (2017) Third Place: Creating a Library Environment that Opens Doors for Collaboration, Value, and Student Achievement (Doctoral dissertation). University of Central Missouri, Warrensburg, MO.

Perrig-Chiello P, Perrig WJ, Uebelbacher A and Stähelin HB (2006) Impact of physical and psychological resources on functional autonomy in old age. Psychology, Health and Medicine 11, 470-482.

Peters DM (2016) Inked: historic African-American beach site as collective memory and group 'third place' sociability on Martha's Vineyard. Leisure Studies 35, 187-199.

Robinson A (1970) Londonderry, Northern Ireland: a border study. Scottish Geographical Magazine 86, 208-221.

Rosenbaum MS, Ward J, Walker BA and Ostrom AL (2007) A cup of coffee with a dash of love: an investigation of commercial social support and third-place attachment. Journal of Service Research 10, 43-59.

Rosso AL, Taylor JA, Tabb LP and Michael YL (2013) Mobility, disability, and social engagement in older adults. Journal of Aging and Health 25, 617-637.

Rozanova J, Keating N and Eales J (2012) Unequal social engagement for older adults: constraints on choice. Canadian Journal on Aging 31, 25-36.

Shergold I and Parkhurst G (2012) Transport-related social exclusion amongst older people in rural Southwest England and Wales. Journal of Rural Studies 28, 412-421.

Shergold I, Parkhurst G and Musselwhite C (2012) Rural car dependence: an emerging barrier to community activity for older people. Transportation Planning and Technology 35, 69-85.

Sherwin S and Winsby M (2011) A relational perspective on autonomy for older adults residing in nursing homes. Health Expectations 14, 182-190.

Shortland V, Redman H and Wildman S (2014) What Next for Community Transport? Insights and Ideas for Action. Hyde, UK: Community Transport Association.

Siren A and Haustein S (2015) What are the impacts of giving up the driving licence? Ageing \& Society 35, 1821-1838.

Smith N, Hirsch D and Davis A (2012) Accessibility and capability: the minimum transport needs and costs of rural households. Journal of Transport Geography 21, 93-101.

Sørensen JF (2018) The importance of place-based, internal resources for the population development in small rural communities. Journal of Rural Studies 59, 78-87.

Spicker P (1990) Social work and self-determination. British Journal of Social Work 20, 221-236.

Steptoe A, Shankar A, Demakakos P and Wardle J (2013) Social isolation, loneliness, and all-cause mortality in older men and women. Proceedings of the National Academy of Sciences 110, 5797-5801.

Stevens M, Glendinning C, Jacobs S, Moran N, Challis D, Manthorpe J, Fernandez JL, Jones K, Knapp M, Netten A and Wilberforce M (2011) Assessing the role of increasing choice in English social care services. Journal of Social Policy 40, 257-274.

Terluin IJ (2003) Differences in economic development in rural regions of advanced countries: an overview and critical analysis of theories. Journal of Rural Studies 19, 327-344.

Treacy P, Butler M, Byrne A, Drennan J, Fealy G, Frazer K and Irving K (2004) Loneliness and Social Isolation Among Older Irish People. Dublin: National Council on Ageing and Older People.

Tregear A and Cooper S (2016) Embeddedness, social capital and learning in rural areas: the case of producer cooperatives. Journal of Rural Studies 44, 101-110.

Tuan YF (2001) Space and Place: The Perspective of Experience. Minneapolis, MN: University of Minnesota Press.

Urry J (2002) Mobility and proximity. Sociology 36, 255-274.

Urry J (2012) Social networks, mobile lives and social inequalities. Journal of Transport Geography 21, 24-30.

Uvnas Moberg K (2013) The Hormone of Closeness: The Role of Oxytocin in Relationships. London: Pinter and Martin. 
Walker J, Orpin P, Baynes H, Stratford E, Boyer K, Mahjouri N, Patterson C, Robinson A and Carty J (2013) Insights and principles for supporting social engagement in rural older people. Ageing \& Society 33, 938-963.

Walsh K, O'Shea E and Scharf T (2012) Social Exclusion and Ageing in Diverse Rural Communities. Galway, Ireland: Irish Centre for Social Gerontology/Healthy Ageing in Rural Communities.

Walsh K, Scharf T and Keating N (2017) Social exclusion of older persons: a scoping review and conceptual framework. European Journal of Ageing 14, 81-98.

Warburton J, Scharf T and Walsh K (2017) Flying under the radar? Risks of social exclusion for older people in rural communities in Australia, Ireland and Northern Ireland. Sociologia Ruralis 57, 459-480.

Westlund AC (2009) Rethinking relational autonomy. Hypatia 24, 26-49.

Zeitler E and Buys L (2015) Mobility and out-of-home activities of older people living in suburban environments: 'Because I'm a driver, I don't have a problem'. Ageing \& Society 35, 785-808.

Ziegler F and Schwanen T (2011) 'I like to go out to be energised by different people': an exploratory analysis of mobility and wellbeing in later life. Ageing \& Society 31, 758-781. 